\title{
Seroprevalencia de hidatidosis humana en la Región de Coquimbo. Chile
}

\author{
MYRIAM LORCA*, MARIO GARRIDO**, MARÍA DEL CARMEN CONTRERAS*, PATRICIA SALINAS*, \\ CRISTIAN ALVAREZ*, MILTON RUIZ*** y PAULO SOTO***
}

\section{HUMAN HYDATIDIC SEROPREVALENCE IN COQUIMBO REGION. CHILE}

Hydatidosis is endemic and enzootic disease in Chile. Previous national studies of seroprevalence showed a rate of $135 \times 10^{5}$, corresponding to approximately 17,000 infected persons. The prevalence of human hydatidosis shows a declining tendency in recent years except in Regions IV, VI, and IX of Chile. Region IV presents higher rates of infection in bovine, ovine, and caprine livestock. A human study was conducted to evaluate the seroprevalence in Region IV (Coquimbo), zone extended between $29^{\circ} 02^{\prime}$ and $32^{\circ} 16^{\prime}$ South latitude. A total of 4,632 blood samples were collected in the provinces of Elqui, Limari, and Choapa. The sample size correspond to approximately $3 \%$ of the rural population of the area in the study. Whole blood samples were collected using filter paper and blood was obtained from the tip of middle finger. ELISA IgG test was used to determine antibodies against $\boldsymbol{E}$. granulosus. The samples were analyzed in two laboratories at the same time. The antigen was prepared from ovine hydatid cysts. The fluid was collected aseptically, centrifuged at 12,000 $\mathrm{g}$ in one laboratory and in the other one, fraction B (Oriol antigen) was used. A seroprevalence of 2,500 $\times 10^{5}$ was determined. This rate is significantly higher than the national one $1.65 \times 10^{5}$, and the regional rate $6.73 \times 10^{5}$ notified in 2004. The rural areas surveyed in the study included mainly cattle farmers. The seroprevalence observed in Limari and Choapa provinces were higher than in Elqui province. The differences may be due to differences in the economic and laboral make-up of the provinces. Further studies are necessary to identify human patients and confirm the infection using additional immunological diagnosis (e.g Western blot) and clinical evaluation with imaging characterization of the patients.

Key words: Hydatid disease, human seroprevalence, Chile.

\section{INTRODUCCIÓN}

La hidatidosis es una zoonosis parasitaria cosmopolita que afecta fundamentalmente a poblaciones humanas y animales de zonas agrícolas y ganaderas. En Chile, esta parasitosis es endémica y enzoótica y hasta el momento no ha podido ser controlada, manteniéndose como un importante problema en Salud Pública ${ }^{1}$.

Su difusión en el ambiente se debe al desconocimiento del problema por la población lo cual conlleva a hábitos y actitudes perniciosas que permiten condiciones favorables para la propagación del ciclo alimentación de los perros

\footnotetext{
* Académicos Unidad Docente Parasitología, Facultad de Medicina, Universidad de Chile

** Interno Escuela Tecnología Médica, Facultad Medicina Universidad de Chile año 2005.

*** Alumnos Escuela Medicina, Facultad de Medicina Universidad de Chile.
} 
con vísceras crudas parasitadas, matanza clandestina de animales y abundancia de perros infectados.

Esta parasitosis es una enfermedad de notificación obligatoria en Chile. El promedio anual, para el período 1973-1983 fue de 790 casos nuevos ${ }^{1.2}$, cifra que ha disminuido notablemente al compararlo con los datos del Departamento de Epidemiología del Ministerio de Salud, registrándose en promedio, 320 y 330 casos notificados para los períodos 1989-1990 y 1999-2000 respectivamente ${ }^{3,4}$.

Hasta 1984, la incidencia de la hidatidosis según egresos hospitalarios presentaba magnitudes cercanas a la observada según notificaciones $(800$ casos notificados versus 1.000 egresos hospitalarios). Sin embargo, posteriormente se produce una marcada y brusca reducción de las notificaciones de esta enfermedad parasitaria junto con una diferencia importante y mantenida entre ambos parámetros (300 casos notificados versus 1.300 egresos hospitalarios en 1985). A partir de 1985, se observa una disminución de los casos notificados en todo el país, con una diferencia respecto de los egresos hospitalarios de desigual magnitud según las regiones ${ }^{5}$.

En 1990, la tasa de incidencia a nivel nacional fue de $1,9 \times 10^{5}$ habitantes según casos notificados y de $9,7 \times 10^{5}$ según egresos hospitalarios.

La hidatidosis, si bien es endémica en Chile, tiene una distribución geográfica heterogénea debido a la fuerte relación existente entre el perro y la actividad ganadera. Las distintas tasas de incidencia a lo largo del país han permitido distinguir cuatro grupos de riesgo ${ }^{6}$ expresadas por 100.000 habitantes. Bajo (hasta 1), Intermedio (1-5), Alto (5,1-30), y Muy Alto (> 30). Al analizar la situación de las regiones con ambos parámetros, notificación y egreso, se obtienen resultados diferentes para los grupos de riesgo, observándose un aumento en el número de regiones que conformarían las zonas de riesgo alto y muy alto.

La tasa de incidencia a nivel nacional de 2,2 x $10^{5}$ registrada en el $2002^{4}$, contrasta con la de 8,2 de 1970, indicando una evidente disminución en las tres últimas décadas ${ }^{4}$. Sin embargo, la subnotificación existente crea una apreciación inadecuada que impide una base para el desarrollo de programas de salud apropiados 5 .

En un estudio a nivel nacional sobre seroprevalencia realizado en sectores urbanos y rurales se encuentra una tasa de $135 \times 10^{5}$ (87 urbanos y 238 rurales), con una estimación probable de 17.002 personas infectadas (10.318 urbanos y 6.648 rurales) ${ }^{7}$.

También la hidatidosis animal ha disminuido en los últimos años, pero aún es la segunda causa de decomisos en los mataderos en todo el país. Esta tendencia a la baja se refleja en la mayoría de las especies excepto en la caprina la cual presenta un aumento cercano al 4\% de 1997 a 1998. Este aumento se aprecia principalmente en la IV Región donde se encontró el mayor incremento, de un 5 a un $14,4 \%$. La especie ovina presentó una disminución importante en comparación a lo registrado en 1997, sólo tres regiones presentaron incrementos (I, IV, VI), donde la IV experimenta un aumento cercano al $10 \%$. Este hecho se debe fundamentalmente a los programas de control en las regiones XI y XII.

En los últimos años la prevalencia humana y animal ha tendido a disminuir en todas las regiones del país, excepto en la IV, VI y IX. Entre ellas destaca la IV Región por mostrar las mayores alzas, tanto en el ganado ovino como en el caprino.

Con el objeto de contribuir al conocimiento actual de la hidatidosis humana, se estudió la seroprevalencia en comunidades rurales ganaderas de la IV Región de Coquimbo con el fin de que dichos resultados sirvan de base para la aplicación de programas de control en la zona.

\section{MATERIAL Y MÉTODOS}

Población en estudio: Estuvo constituida por los habitantes de las comunidades rurales ganaderas de las provincias de Elqui, Limarí y Choapa pertenecientes a la IV Región de Coquimbo zona extendida entre $29^{\circ} 02^{\prime}$ y $32^{\circ} 16^{\prime}$ latitud Sur. Se obtuvo 4.632 muestras, mediante muestreo aleatorio sistemático representativo de la región, según localidades. Las muestras fueron equivalentes al 3\% de la población rural total de la IV Región, según la base de datos del Servicio Agrícola y Ganadero y a la estimación del Servicio de Salud de la IV Región ${ }^{9}$.

Técnica empleada: Según las normas bioéticas del manejo de muestras humanas, la obtención de cada una de ellas, estuvo supeditada a la aprobación de los individuos. 
Las muestras de sangre ${ }^{10,11}$ obtenidas del pulpejo del dedo medio, fueron colectadas en papel filtro Whatman $\mathrm{N}^{\circ} 1$, en una superficie de $5 \mathrm{~cm}^{2}$. Una vez secos a temperatura ambiente, se acondicionaron en sobres "ad hoc", evitando que absorbieran humedad y se mantuvieron a temperatura ambiente hasta su envío al laboratorio, donde se eluyó una superficie estandarizada en buffer fosfato salino.

A cada eluído se les efectuó ELISA $\operatorname{IgG}^{12,13}$. Dicha técnica se realizó en forma paralela en dos laboratorios de rutina en inmunodiagnóstico parasitológico.

Se usó como antígeno líquido hidatídico hepático ovino, aislado en forma estéril, centrifugado a $12.000 \mathrm{~g}$ en un laboratorio y en el otro, el antígeno estuvo constituido por la fracción B o antígeno de Oriol.

El eluído a un volumen de $100 \mu \mathrm{l}$ fue depositado en placas sensibilizadas con antígeno, incubadas y lavadas según los protocolos previos.

El segundo anticuerpo constituido por anti IgG humana marcada con peroxidasa (SIGMA) a dilución óptima y como sustrato específico (ortofelinendiamina 0,04\%, $40 \mu \mathrm{H}_{2} \mathrm{O}_{2} 30 \%$ en buffer citrato $0,1 \mathrm{M} \mathrm{pH} 5$ ). La detención de la reacción se efectuó con $50 \mu \mathrm{l}$ de $\mathrm{H}_{2} \mathrm{SO}_{4} 4 \mathrm{M}$ y la lectura se practicó a $490 \mathrm{~nm}$ en un densitómetro Organon Teknika.

Se aceptó como positivos aquellos eluídos que tuvieron lecturas de DO sobre el valor de corte en ambas técnicas de ELISA.

Análisis de datos: Los datos de cada persona fueron introducidos en la planilla de cálculos de Microsoft Excel 2000 de Microsoft Corp ${ }^{\mathrm{TM}}$, siendo analizados los resultados con el programa Epi Info 6.04 (CDC, Atlanta Georgia, USA).
Tabla 1. Seroprevalencia de la hidatidosis humana en la zona rural de la IV Región. Frecuencia según provincias

\begin{tabular}{lcrr}
\hline Provincia & $\mathbf{N}^{\circ}$ Examinados & \multicolumn{2}{c}{ Positivos } \\
& & n & $\%$ \\
\hline Choapa & 1.469 & 15 & 1 \\
Limarí & 1.705 & 61 & 3,6 \\
Elqui & 1.458 & 40 & 2,7 \\
Total & 4.632 & 116 & 2,5 \\
\hline
\end{tabular}

\section{RESULTADOS}

La seroprevalencia encontrada en comunidades rurales ganaderas de la IV Región de Coquimbo, alcanzó a un 2,5\% lo cual se evidencia en la Tabla 1, donde las prevalencias de las provincias de Limarí y Elqui fueron superiores a la de Choapa $(\mathrm{p}<0,01)$.

En la Tabla 2, se analiza la prevalencia de la hidatidosis en la IV Región de Coquimbo según sexo y grupo etáreos, donde se destaca el hecho de que un $25 \%$ de los casos eran menores de 20 años y con una relativa mayor frecuencia en mujeres $(\mathrm{p}>0,01)$.

En la Tabla 3, se muestra la seroprevalencia para hidatidosis por comunas de la Provincia del Choapa, Limarí y Elqui. En la primera, un 73,3\% de los casos eran procedentes de las comunas de Los Vilos e Illapel. En la provincia de Limarí se destaca la mayor frecuencia de las comunas de Río Hurtado y de Monte Patria, las cuales reúnen el $68,9 \%$ del total de la provincia. Entre las diversas comunas del Elqui, Vicuña presentó la mayor seroprevalencia.

Tabla 2. Resultados serológicos para hidatidosis de acuerdo a edad y sexo en 4.632 muestras examinadas

\begin{tabular}{|c|c|c|c|c|c|c|c|c|c|}
\hline \multirow{3}{*}{$\begin{array}{l}\text { Grupo } \\
\text { etario }\end{array}$} & \multicolumn{3}{|c|}{ Hombres } & \multicolumn{3}{|c|}{ Mujeres } & \multicolumn{3}{|c|}{ Total } \\
\hline & \multirow[t]{2}{*}{$\mathbf{N}^{\circ}$ exam. } & \multicolumn{2}{|c|}{ Caso } & \multirow[t]{2}{*}{$\mathbf{N}^{\circ}$ exam. } & \multicolumn{2}{|c|}{ Casos } & \multirow[t]{2}{*}{$\mathbf{N}^{\circ}$ exam. } & \multicolumn{2}{|c|}{ Casos } \\
\hline & & $\mathbf{n}$ & $\%$ & & $\mathbf{S}$ & $\mathbf{n}$ & & $\%$ & n \\
\hline $0-9$ & 530 & 5 & 0,9 & 574 & 5 & 0,9 & 1.104 & 10 & 0,9 \\
\hline $10-19$ & 513 & 7 & 1,4 & 490 & 12 & 2,4 & 1.003 & 19 & 1,9 \\
\hline $20-29$ & 169 & 2 & 1,2 & 339 & 17 & 5,0 & 508 & 19 & 3,7 \\
\hline $30-39$ & 181 & 9 & 5,0 & 387 & 13 & 3,4 & 568 & 22 & 3,9 \\
\hline $40-49$ & 215 & 3 & 1,4 & 267 & 7 & 2,6 & 482 & 10 & 2,1 \\
\hline $50-59$ & 168 & 4 & 2,4 & 210 & 8 & 3,8 & 378 & 12 & 3,2 \\
\hline$>60$ & 284 & 12 & 4,2 & 305 & 12 & 3,9 & 589 & 24 & 4,1 \\
\hline Totales & 2.060 & 42 & 2,0 & 2.572 & 74 & 2,9 & 4.632 & 116 & 2,5 \\
\hline
\end{tabular}


Tabla 3. Seroprevalencia de la hidatidosis humana en las provincias del Choapa, Limarí y Elqui. Frecuencia por comunas

\begin{tabular}{lll}
\hline Comunas & $\mathbf{N}^{\circ}$ Examinados & \multicolumn{2}{c}{ Casos } \\
& $\mathrm{n} \quad \%$ \\
\hline
\end{tabular}

\begin{tabular}{lrrr}
\hline Provincia Choapa & & & \\
Los Vilos & 245 & 6 & 2,4 \\
Illapel & 173 & 5 & 2,9 \\
Canela & 889 & 2 & 0,2 \\
Salamanca & 162 & 2 & 1,2 \\
Provincia Limarí & & & \\
Monte Patria & 709 & 30 & 4,2 \\
Río Hurtado & 219 & 12 & 5,5 \\
Punitaqui & 79 & 3 & 3,8 \\
Ovalle & 335 & 7 & 2,1 \\
Combarbalá & 363 & 9 & 2,5 \\
Provincia Elqui & & & \\
La Higuera & 91 & 6 & 6,6 \\
La Serena & 424 & 3 & 0,7 \\
Vicuña & 502 & 22 & 4,4 \\
Coquimbo & 247 & 0 & 0,0 \\
Paihuano & 148 & 4 & 2,7 \\
Tongoy & 46 & 5 & 10,9 \\
Totales & 4.632 & 116 & 2,5 \\
\hline
\end{tabular}

\section{DISCUSIÓN}

La tasa global de la hidatidosis encontrada en la IV Región equivale a una prevalencia estimada de $2.500 \times 10^{5}$, cifra notablemente superior a la tasa de $1,65 \times 10^{5}$ a nivel nacional y de $6,73 \times 10^{5}$ para la Región de Coquimbo notificadas en el $2004^{4}$. Este hecho no es sorprendente, puesto que generalmente la sintomatología se presenta en forma escasa o poco definida, pudiendo mantenerse por largo tiempo asintomático. Estudios efectuados en cadáveres demostraron que un $63,9 \%$ fueron hallazgos de autopsia ${ }^{14}$.

Los datos obtenidos en este estudio, son inferiores a los encontrados en las áreas rurales de la misma región por algunos de nosotros ${ }^{7}(0,2$ versus $2,5 \%$ ), hecho que podría ser explicado por el mayor número de muestras estudiadas en esta oportunidad y a la realización simultánea de dos técnicas de ELISA, con dos antígenos diferentes, métodos de reconocida sensibilidad y especificidad $^{12-13}$.

En líneas generales, la toma de sangre en papel filtro es considerada ventajosa y aceptada para estudios seroepidemiológicos ${ }^{15-16-17}$.

Las prevalencias encontradas para las provincias de Limarí y Choapa, fueron superiores, en forma significativa, al número de infectados encontrados para la Provincia del Elqui ( $\mathrm{p}<$ $0,01)$, diferencia que podría ser explicada debido al tipo de actividades económicas y laborales. Las dos primeras regiones tendrían un mayor factor de riesgo de contraer la infección las dos acumulan un $65,5 \%$ del total de positivos encontrados para la Región de Coquimbo, debido a la actividad ganadera. En tanto en la provincia del Elqui con un $34,4 \%$ del total de positivos, la actividad económica fundamental es la vitivinícola.

Este resultado es concordante con el hallazgo de coproantígenos de E. granulosus en 3.600 perros de la Región donde sólo el 17,6\% de los perros infectados provenía de la Provincia de Elqui, en comparación al $60,6 \%$ de prevalencia para las otras provincias ${ }^{18}$.

Al analizar la distribución de los casos positivos por edad - tanto los resultados generales de la Región como los por Provincia - destaca el hecho que la infección es adquirida en edades tempranas, situación que es indicativa de un ambiente altamente contaminado con huevos del cestode. Este hecho unido a los malos hábitos higiénicos de los niños y de sus manipuladores de alimentos transforma la posibilidad de infección en un gran riesgo.

Tradicionalmente, se ha descrito que la hidatidosis se presenta con mayor frecuencia en hombres ${ }^{6,7}$. Sin embargo, en el presente estudio se observa a nivel regional, una mayor frecuencia relativa en mujeres, la cual no fue significativa ( $>$ > 0,01). Tampoco hubo diferencias significativas a nivel de las provincias, siendo superior la frecuencia obtenida en hombres para Choapa, en mujeres para Limarí y prácticamente iguales para Elqui.

Esta mayor frecuencia de mujeres positivas podría estar en relación a que en el último tiempo, en el Norte del país las mujeres y niños participan activamente en labores agrícolas.

Cabe destacar la importancia de esta zoonosis en la salud humana y la economía del país, puesto que ocasiona daño al hombre por la enfermedad y a la sociedad por los costos laborales y del tratamiento.

Las altas tasas encontradas son el reflejo de lo que sucede en comunas rurales, donde la escasa educación sanitaria y el inadecuado faenamiento y conservación de las carnes, son factores que inciden en la infección de un importante número 
de perros puedan, con la consiguiente contaminación del ambiente con huevos de $E$. granulosus y el consecuente riesgo para los hospederos intermediarios de adquirir la infección.

El escaso conocimiento sobre hidatidosis de las personas se relaciona directamente con su nivel educacional generalmente insuficiente, especialmente en lo relativo a la prevención de la enfermedad.

Los resultados obtenidos refuerzan la necesidad de poner en práctica en lo educativo creando conciencia en evitar la infección de los hospederos susceptibles (principalmente el hombre), en el faenamiento de los animales de abastos para evitar la infección del perro, además del tratamiento anti echinococcósico masivo de los perros.

Por último, debido a que los resultados obtenidos, se basaron en un screening seroepidemiológico, donde se tiene una aproximación de la realidad, es importante considerar el estudio de los casos positivos a nivel serológico - en suero y con técnicas confirmatorias como Western blott - junto con un estudio clínico e imagenológico.

\section{RESUMEN}

Estudio previos de seroprevalencia de hidatidosis en Chile, realizados en sectores urbanos y rurales encontraron una tasa de $135 \mathrm{x}$ $10^{5}$, con una estimación probable de 17.002 personas infectadas. En los últimos años la prevalencia humana y animal ha tendido a disminuir en todas las regiones del país, excepto en la IV, VI y IX. Entre ellas destaca la IV Región por mostrar las mayores alzas, tanto en el ganado ovino como en el caprino.

Con el objeto de contribuir al conocimiento actual de la hidatidosis humana, se estudió la prevalencia serológica en comunidades rurales ganaderas de la IV Región de Coquimbo con el fin de que dichos resultados sirvan de base para la aplicación de programas de control en la zona. Se estudiaron 4.632 muestras de habitantes de las provincias de Elqui, Limarí y Choapa. La selección del grupo se efectuó por muestreo aleatorio sistemático representativo de la región, según localidades y equivalentes al 3\% de la población rural total de la IV Región.

Las muestras de sangre obtenidas del pulpejo del dedo medio, fueron colectadas en papel filtro, según las normas bioéticas, estando supeditado al consentimiento de las personas. A cada eluído se les efectuó ELISA IgG. En forma paralela en dos laboratorios de rutina de inmunodiagnóstico parasitológico. Como antígeno se usó líquido hidatídico hepático ovino, aislado en forma estéril, centrifugado a $12.000 \mathrm{~g}$ en un laboratorio y en el otro el antígeno estuvo constituido por la fracción B o antígeno de Oriol.

La seroprevalencia de la hidatidosis encontrada en comunidades rurales ganaderas de la IV Región de Coquimbo, alcanzó a un $2,5 \%$. La tasa global encontrada en la IV Región equivale a una prevalencia estimada de $2.500 \mathrm{x}$ $10^{5}$, cifra notablemente superior a la tasa de 1,65 x $10^{5}$ a nivel nacional y de $6,73 \times 10^{5}$ para la Región de Coquimbo notificadas en el 2004.

Las prevalencias encontradas para las provincias de Limarí y Choapa, fueron superiores, en forma significativa, al número de infectados encontrados para la Provincia del Elqui, diferencia que podría ser explicada debido al tipo de actividades económicas y laborales. Las altas tasas encontradas son el reflejo de lo que sucede en comunas rurales, donde la escasa educación sanitaria y el inadecuado faenamiento y conservación de las carnes, son factores de riesgo para que un importante número de perros puedan infectarse.

Debido a que los resultados obtenidos, se basaron en un screening seroepidemiológico, es importante considerar el estudio de los casos positivos a nivel serológico - en suero y con técnicas confirmatorias como Western blott junto con un estudio clínico e imagenológico.

\section{REFERENCIAS}

1.- SERRA I. Hidatidosis humana en Chile. Un problema de salud pública vigente. Rev Méd Chile 1986; 114 : 1090-7.

2.- SCHENONE H, ROJAS A, VILLARROEL F. SCHENONE H. (hijo). Algunos aspectos de la epidemiología de la hidatidosis humana y animal en Chile, con especial referencia al decenio 1975 - 1984. Bol Chil Parasitol 1987; 42: 49-58.

3.- MINISTERIO DE SALUD DE CHILE. Anuarios de Enfermedades Obligatorias. Santiago 1989-1998.

4.- www.minsal.cl

5.- SERRA I, ARAYA C, ARANEDA J. SERRA V. Situación actual de la hidatidosis en Chile. Dos propuestas de corrección de su subnotificación. Rev Méd Chile 1995; 123: 659-69.

6.- SERRA I, ARAYA C, ARANEDA J, SERRA V. 
Análisis regional de la hidatidosis humana y animal en Chile, 1989-1993. Bol Chil Parasitol 1996; 51: 3-12.

7.- SCHENONE H, CONTRERAS M DEL C, SALINAS $\mathrm{P}$, et al. Hidatidosis humana en Chile. Seroprevalencia y estimación del número de personas infectadas. Bol Chil Parasitol 1999; 54: 70-3.

8.- GONZÁlEZ C G, MOREIRA R, MONREAL Z. Servicio Agrícola y Ganadero (SAG) del Gobierno de Chile. Subdepartamento de Vigilancia Epidemiológica Boletín N 351998 pp. 9-24.

9.- INSTITUTO NACIONAL DE ESTADÍSTICAS. Censo de Población y Vivienda. Chile 1992.

10.- GOLDSMITH R S, KAGAN IG, ZARATE R. Low Toxoplasma antibody prevalence in serologic surveys of human in southern Mexico. Arch Invest Med (Méx) 1991; 22: 63-73.

11.- GUIMARAES M C, CASTILHO E A, CELESTE B J, et al. Almacenamiento a largo plazo de $\operatorname{IgG}$ e IgM en papel filtro para su uso en encuestas seroepidemiológicas de enfermedades parasitarias. Bol Ofic Sanit Panamer 1986; 100: 129-42.

12.- GARCÍA A, DENEGRI M, LJUNGSTROM I, LORCA M. Identification of a immunodominant antigens by immunoelectrotransfer in hydatid fluid. Bol Chil Parasitol 1998; 53: 58-64.
13.- CONTRERAS M del C, GALLO S, SALINAS P, et al. Evaluación de la ELISA IgG usando un antígeno purificado en el diagnóstico de la hidatidosis humana. Bol Chil Parasitol 1994; 49: 24-30.

14.- SCHENONE H. La Cisticercosis y la Hidatidosis no siempre producen en el humano patología detectable. Bol Chil Parasitol 1989; 44: 63-65.

15.- BIFFINAH JONES M A, PALMER S R. Human hydatid disease: evaluation of an ELISA for diagnosis population screening and monitoring of control programes. J Med Microbiol 1993; 39: 48-52.

16.- GONZÁLEZ ROIZ M C, CARMONA PÍA C, PÉREZ GIRALDO C, et al. ELISA IgG as screening test for the research of true prevalence of human hidatidosis in Badahoz, Spain. Eur J Epidemiol 1998; 4: 439-44.

17.- COLTORTI E, GUARNETA E, LARRIEU E, et al. Seroepidemiology of human hidatidosis: use of dried blood samples on filter paper. Trans R Soc Trop Med Hyg 1988; 82: 607-610.

18.- SABELLE C. SAG. Ministerio de Agricultura (Comunicación Personal).

Agradecimientos: La presente investigación se llevo a cabo con aportes del Proyecto MINSAL Occ. 5303 y la Network SIDA / SAREC, y por lotanto les agradecemos sus aportes. 